\title{
DECISION MAKING IN SUPPLY CHAINS AND VALUE NETWORKS: THE BEER GAME EVOLUTION $^{\mathrm{a}}$
}

\author{
Paolo Spagnoletti \\ CeRSI-LUISS Guido Carli University \\ Via T. Salvini 2, 00198 Roma - Italy \\ pspagnoletti@luiss.it \\ Edoardo D'Atri \\ ICT Academy \\ Via T. Mertel 30, 00167 Roma, Italy \\ e.datri@ict-academy.it \\ Alessandro D'Atri \\ CeRSI-LUISS Guido Carli University \\ Via Salvini 2, Roma, Italy \\ datri@luiss.it
}

\begin{abstract}
New trends in inter-organization configurations are challenging the traditional concept of supply chain. Concepts such as Virtual Enterprise were introduced to describe scenarios in which manufacturers operate as nodes within a network of suppliers, customers, engineers, and other specialized service functions. Our aim is to build a simulation tool based on the rules of the Beer Game that includes the variables of a virtual enterprise, VirtuE in particular, and risk management in order to understand the strategies underlying the subject's behavior in the face of risk within a means-end chain. The simulation tool will contribute to understanding the complexity of managing decision making in supply chains and networks. This study presents the tests carried out on the original game, the new variables introduced, and the simulation results ${ }^{\mathrm{b}}$.
\end{abstract}

Keywords: Beer Game, Virtual Enterprises, Transaction Costs, Supply Chain Management

\footnotetext{
${ }^{a}$ This article is based on the previous work presented at the 13th IFAC Symposium on Information Control Problems in Manufacturing .

${ }^{b}$ We thank all the partners of the SFIDA PMI project.
} 


\section{INTRODUCTION}

The Beer Game was developed in the 1960s by the MIT Sloan System Dynamics Group $^{2,3}$ as a didactic tool to simulate information and material flows along the supply chain from the factory to the retailer. The main goal of this business game is to show the existence and the characteristics of the "bullwhip effect", 5. This phenomenon represents the propagation and amplification of orders as they pass upstream in a supply chain pipeline. It causes uncertainty for managers who then create stock and/or maintain excess capacity leading to increased total costs. The Beer Game has been widely used to simulate the "bullwhip" effect but also other phenomena such as the "backlash" effect or reflection of shipments in response to amplification in orders ${ }^{5}$.

The Beer Game has four players: retailer, wholesaler, distributor, and factory. These players are distributed along a single supply chain, communicating with each other only about the beer orders that each player sends to the nearest player. The only exception refers to the retailer's order, represented by the requests of the final customer, which is established in advance and are not known by other participants.

Many questions have been posed about the limitations of the original Beer Game (for convenience, we will refer to it as the "MIT Beer Game"), and new versions have been proposed. Kaminsky and Simchi-Levi ${ }^{6}$ highlighted the limits of the Beer Game in providing a better way to manage the supply chain. They also highlighted that the game structure does not provide a realistic view of the behaviors involved in the supply chain. Indeed, a linear chain does not allow any choice about the suppliers. Kimbrough et al. ${ }^{7}$ described players' behavior when they join the supply chain. In their view, players are not motivated to share information; their choices are taken in situations of bounded rationality, and their individual rational behavior sometimes goes against the group's interests. These and other critics $^{8}$ gave rise to a number of digital versions of the MIT Beer Game or similar tools ${ }^{9}$ that take into account the variables involved. For instance, in order to introduce the concept of optimization, Kumara et al. proposed a new version of the Beer Game in which a single player (acting as supply chain coordinator) sets the model parameters and the model is executed in a probabilistic manner ${ }^{10}$. Furthermore, a recent work underlines the importance to consider that decision makers evaluate the prospects for gains and losses from psychological reference points that shift over time following some random events instead of seeking to maximize their utility under an unvarying formula ${ }^{11}$. 
Other studies concentrate more on the structural and topological aspects of the Beer Game by stressing the fact that the supply chain evolves into network solutions based on collaborative and communicative interactions between two or more enterprises and oriented towards the coordination of different activities ${ }^{3,8,13,14}$. Indeed, companies abandoned the perspective that each supply chain member performs a distinct value-adding task and instead regard both suppliers and customers as potential co-producers of value ${ }^{15}$. These trends in inter-organization configurations led to the concept of Virtual Enterprise to characterize the global supply chain of a single product in an environment of dynamic networks between companies engaged in many different complex relationships. In a Virtual Enterprise (VE), manufacturers no longer produce complete products in isolated facilities. They operate as nodes in a network of suppliers, customers, engineers, and other specialized service functions ${ }^{16}$, 17, 18. In such contexts, transaction costs are a key issue to be taken into account ${ }^{19,20}$, and some formal representation has been proposed in the literature for modeling issues such as transaction costs and risks in the VirtuE model ${ }^{21}$.

In order to introduce the students to various supply chain management topics arising from these structural aspects, a new version of the game was proposed by Riemer as a teaching tool for extending the initial version ${ }^{22}$. This new version considers a parallel supply chain interaction network in which two customers, two retailers, one distribution center, two manufacturers, and three vendors interact. According to the author, the adoption of this teaching tool is highly effective in helping students understand the complexity and dynamics of parallel supply chains, identify the operational issues, and examine the potential tactical and strategic solutions. In fact, the new game helps introduce and facilitate discussions about topics such as speculation/postponement, risk-pooling, control systems, and technology in supply chain integration.

This paper aims to contribute to the body of knowledge on decision making for supply chain management by introducing new versions of the existing simulation tools that embed aspects relevant to virtual enterprises. In particular, the VirtuE model has been taken into consideration for developing a Beer Game 2.0 and a Beer Game 2.1, the characteristics of which will be illustrated together with the simulation results.

We believe that these evolutions of the Beer Game allow increases in the player's understanding of the strategies that underlie managers' decision making. Our assumption is that the study of players' policies and behaviors is particularly relevant in the presence of multiple suppliers and transaction risk. 
In the next sections, we first introduce our research method, then describe the main characteristics of each version of the Beer Game in terms of rules, objectives, and simulation results. A short discussion and a comparative analysis focused on costs and policies will follow. Finally, we summarize the findings by providing comments on the limitation of this approach and possible further developments.

\section{RESEARCH METHOD}

This study is based on the results of a series of experiments conducted during the Expert Training Course (ETC) in "collaborative management of the supply chain" which has been organized in the context of a national research project called SFIDA PMI ${ }^{\mathrm{c}}$. The ETC has a special focus on interoperability issues and critical relationships among companies in many productive sectors. We tested the standard version of the MIT Beer Game, and our results were in line with previous findings. We also designed three alternative versions of this simulation game in order to highlight the specific features of modern supply chains such as the network enterprise structure and the possibility of transaction failures. We analyzed the policies underlying the behavior of players involved in supply chains and networks through simulations. These simulations also led us to obtain a proof of concept of the new versions of the Beer Game that are now available for further investigations about the cooperation dynamics of the supply network participants.

During the simulations, players were supposed to make their choices independently from any given policy and with the goal of reducing their own stock costs. In order to compare their strategies ${ }^{23}$ and their willingness to take risks, we defined the following policy matrix based on two variables: unsold stock and placed order.

Four possible strategies have been identified depending on the level of the two variables: Never Backlog, Full Warehouse, Low Cost, and Pass Order. We will refer to these definitions for discussing and classifying player behaviors.

\footnotetext{
${ }^{c}$ More information on the SFIDA PMI project is available on the website (www.cersi.it) of the Research Centre on Information Systems - LUISS Guido Carli University, Roma, Italy.
} 
Table 1. Strategies identified in beer game simulation

\begin{tabular}{|c|c|c|c|}
\hline & \multicolumn{2}{|c|}{ UNSOLD STOCK } \\
\hline & & HIGH & LOW \\
\hline \multirow{2}{*}{ 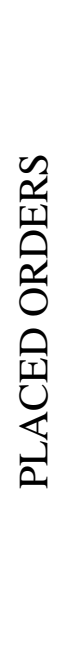 } & $\begin{array}{l}\text { 焉 } \\
\end{array}$ & $\begin{array}{l}\text { NEVER BACKLOG } \\
\text { Condition: variable demand } \\
\text { Target: executing orders } \\
\text { Risk: collapse or decrease in } \\
\text { demand generates high storage } \\
\text { costs }\end{array}$ & $\begin{array}{l}\text { FULL WAREHOUSE } \\
\text { Condition: predicting an } \\
\text { increase in demand } \\
\text { Target: increasing stock levels } \\
\text { to avoid backlogs } \\
\text { Risk: oversized warehouse }\end{array}$ \\
\hline & ב- & $\begin{array}{l}\text { LOW COST } \\
\text { Condition: warehouse is able } \\
\text { to respond to positive changes } \\
\text { in demand } \\
\text { Target: stable inventories with } \\
\text { predictable costs } \\
\text { Risk: balanced }\end{array}$ & $\begin{array}{l}\text { PASS ORDER } \\
\text { Condition: constant demand } \\
\text { Target: low warehouse costs } \\
\text { Risk: risk of backlog due to a } \\
\text { variable demand increase and } \\
\text { delays in good delivery }\end{array}$ \\
\hline
\end{tabular}

\section{BEER GAME 1.0}

\subsection{Description}

On the basis of the studies on virtual enterprises, transaction costs, and risk management, we defined three versions of the MIT Beer Game in order to analyze the policies that affect the supply chain actors' behavior. The first version (also referred to as "Beer Game 1.0") is very similar to the original version in terms of chain structure. It differs only in the shape of the market requests since we applied random orders ranging in a $0 \_10$ set of values corresponding to 44 cards taken from a deck. The motivation for this choice lies in the fact that our goal differs from the traditional MIT Beer Game, which is mainly focused on the concept of bullwhip effect. We prefer to analyze the simulation results in a random market request scenario.

The game has four players with the following roles: retailer, wholesaler, distributor, and factory. All of them are on the same linear chain.

The retailer receives a beer order from the final consumer (card deck), hiding it from the other players; then, according to his/her personal policy, the retailer forwards an order to the wholesaler. The wholesaler sends the order to the distributor, and when the order reaches the factory, the last 
player decides how many beers to produce. Each step has a 2-week lead time for both goods and information. The quality of each single policy undertaken by the players is assessed on the basis of stock cost values. In other terms, players share the common goal of reducing their own stock costs and are free to define a personal policy according to their understanding of the situation and their personal attitude toward risk.

In order to support data collection and analysis, each player uses an electronic spreadsheet, which includes data related to sent and received orders and goods.

\subsection{Simulation}

In this simulation, the bullwhip effect is not as clear as in the original simulation because, at the beginning of the game, players try to increase their inventories and thus the related costs. In this case, backlog events are briefer than the original simulation, which is the most important element of the bullwhip effect. This is mainly due to the demand faced by the players, which is different from in the MIT Beer Game. This has a stable value at the beginning of the game, then an instant positive change that leads to a new constant higher value for the rest of the game. This step increase inevitably leads players to backlogs.

In Beer Game 1.0, we explored the case of the stochastic demand, where demand was randomly generated from a known distribution, e.g., uniformly distributed between a set of values ranging from 0 to 10 . At first, players increased stock levels to avoid backlog events. Then, they tried to estimate the variation range production chain. The cost analysis of the first simulation shows very similar levels to those in the MIT Beer Game costs (higher in players farthest from the final market). 


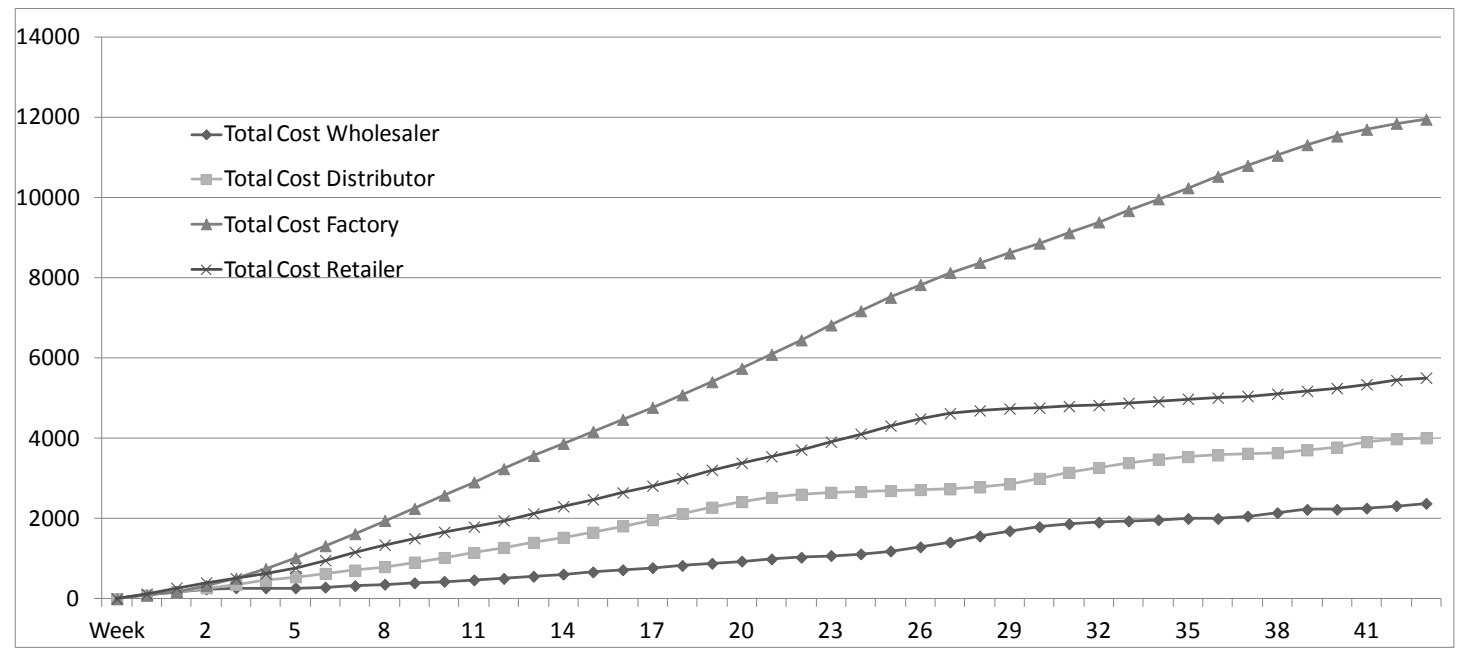

Figure 1. Beer game 1.0 player's costs

The only significant differences noted were in the costs of the final retailer (higher in comparison to the two middlemen, i.e., equal to 5.508). This can be explained as follows: using a Never Backlog strategy and knowing the variation of the final demand and the decrease of the goods required by the market, the distributor employs an initial strategy aimed at increasing warehouse levels during the first weeks and then maintaining a constant request equal to the average expected level (equal to 5). In the original game, goods required by the market had a constant value equal to 8; in the simulation, the average value was approximately 4.75 . Despite taking into account the producer's total costs (reaching the value of 11.952), the lack of bullwhip effect caused many difficulties for selling warehouse stock. As to the middlemen, the wholesaler provides interesting insights: $\mathrm{He}$ adopted the Just in Time model but, due to the delay of orders and delivery of goods (leading to a 4-week postponement), he was not able to avoid an oversized warehouse or backlog events. However, he managed to have the lowest cost (equal to 2.376).

\section{BEER GAME 2.0}

\subsection{Description}

In this version of the game, Beer Game 2.0, we introduced some differences in comparison to the previous version. First, players are not in the same linear chain. Starting from the retailer, a new diagram is created, and the two middlemen are placed on parallel lines. Second, the retailer can choose to send the orders to both wholesalers or only to one of them. Finally, 
the factory manager, on the basis of his own policy and stock levels, can choose how many orders to manage.

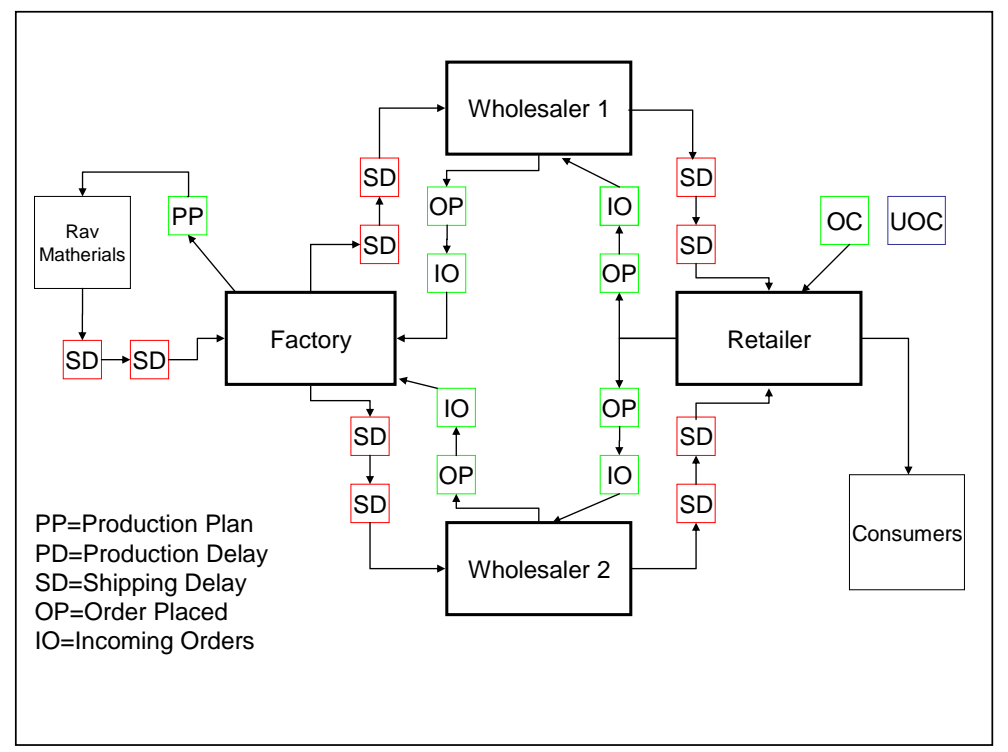

Figure 2. Beer game 2.0 supply network

In this simulation, we used another spreadsheet and, unlike the previous version (1.0), it is customized to each player. First, the orders placed by the two wholesalers are separated and distinguished. Second, the factory manager can choose which order to deal with on the basis of his/her personal policy. Third, the retailer dashboard is used to register the beers received by the two different wholesalers, their incoming orders, and orders placed.

\subsection{Simulation}

The second simulation provided interesting results. The players' total costs are proportional to the levels achieved in simulation Beer Game 1.0 (the factory is the player with the highest cost, followed by the retailer who adopted the same strategy and finally the two wholesalers). The sum of the wholesalers' total costs is equal to the retailer's cost during this simulation (after 44 weeks, the retailer scored 14.712, and both wholesalers scored 14.574). 


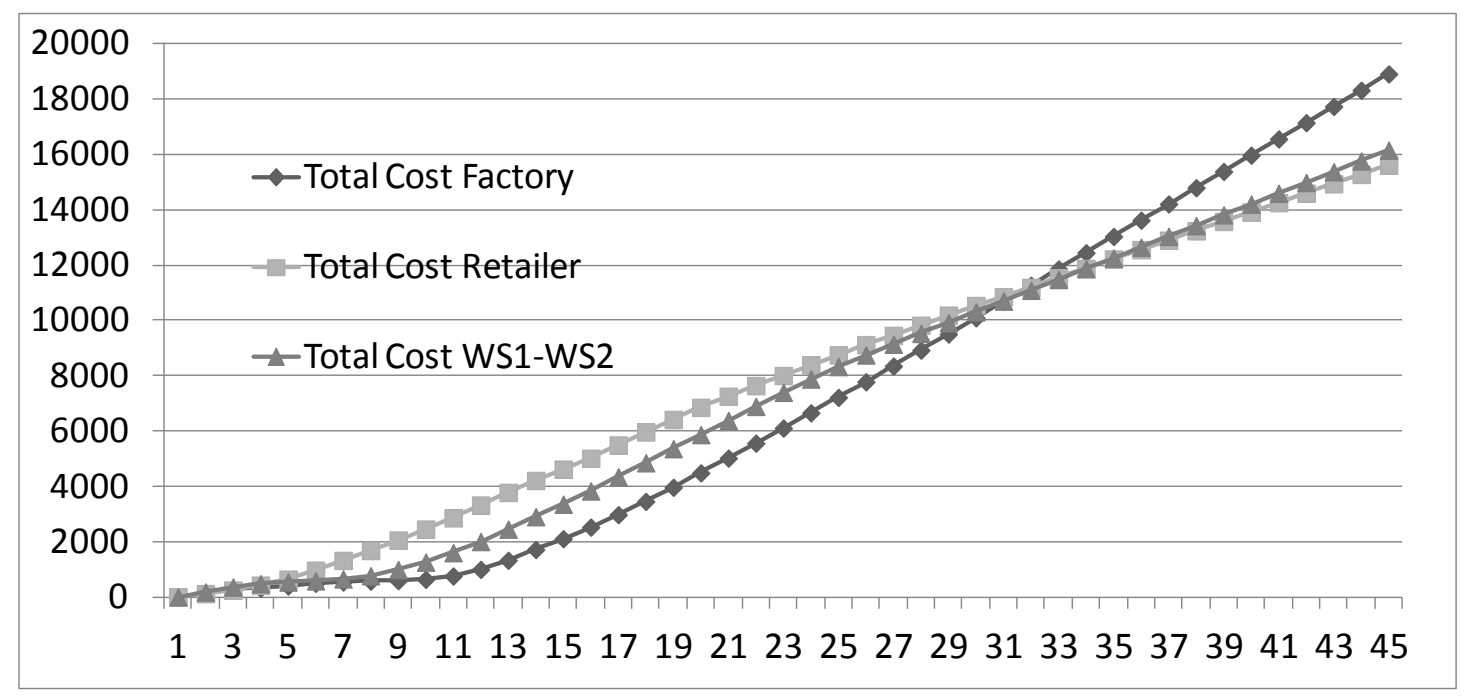

Figure 3. Beer game 2.0 player's costs

The factory generally has the highest costs (17.490) because it is the player farthest from the market and the information relating to the demand. The sum of the two wholesalers' costs is very similar to the retailer's cost. From this perspective, the retailer has high costs due to the implementation of a Full Warehouse strategy, which is not the most suitable strategy in a market with such a low variability.

\section{BEER GAME 2.1}

\subsection{Description}

In comparison to the previous version, Beer Game 2.1 takes risk management into account. The two wholesalers might not be able to receive the goods sent by the factory. In that case, they can transfer the beers available in stock and try to fulfill the new orders. The other players do not know how many times this could happen. This variable is predetermined: The high-risk wholesaler has higher probability to fail $(\mathrm{P}=0.5)$ and lower backlog costs:

$$
\mathrm{Cr}=\mathrm{C} *(1-\mathrm{P})
$$

The low-risk wholesaler has a lower probability to fail $(\mathrm{P}=0.16)$ and higher backlog costs.

In particular: 
- The high-risk wholesaler pays 3 euros per week for each beer crate in the warehouse and 6 euros for each backlog order.

- The low-risk wholesaler pays 5 euros per week for each beer crate in the warehouse and 10 euros for each backlog order.

- The retailer does not know which of the wholesalers poses the greatest risk, but he can try to implement policies to find this out (for example, by estimating failed orders).

\subsection{Simulation}

Analyzing the total costs of simulation Beer Game 2.1, we observed that the factory has the highest costs (28.752) as well as in other simulations. The two wholesalers adopted different strategies; the low-risk wholesaler adopted the Low Cost strategy, allowing him to successfully meet the changes in demand, while the high-risk player, much inclined to take risks, adopted the Pass Order strategy to reduce the inventory's cost. Nevertheless, the wholesalers' costs were lower in comparison to the retailer's. The total of their cost (i.e., 10.348) is less than the cost of the retailer (i.e., 11.430) because the high-risk wholesaler maintained a Pass Order strategy.

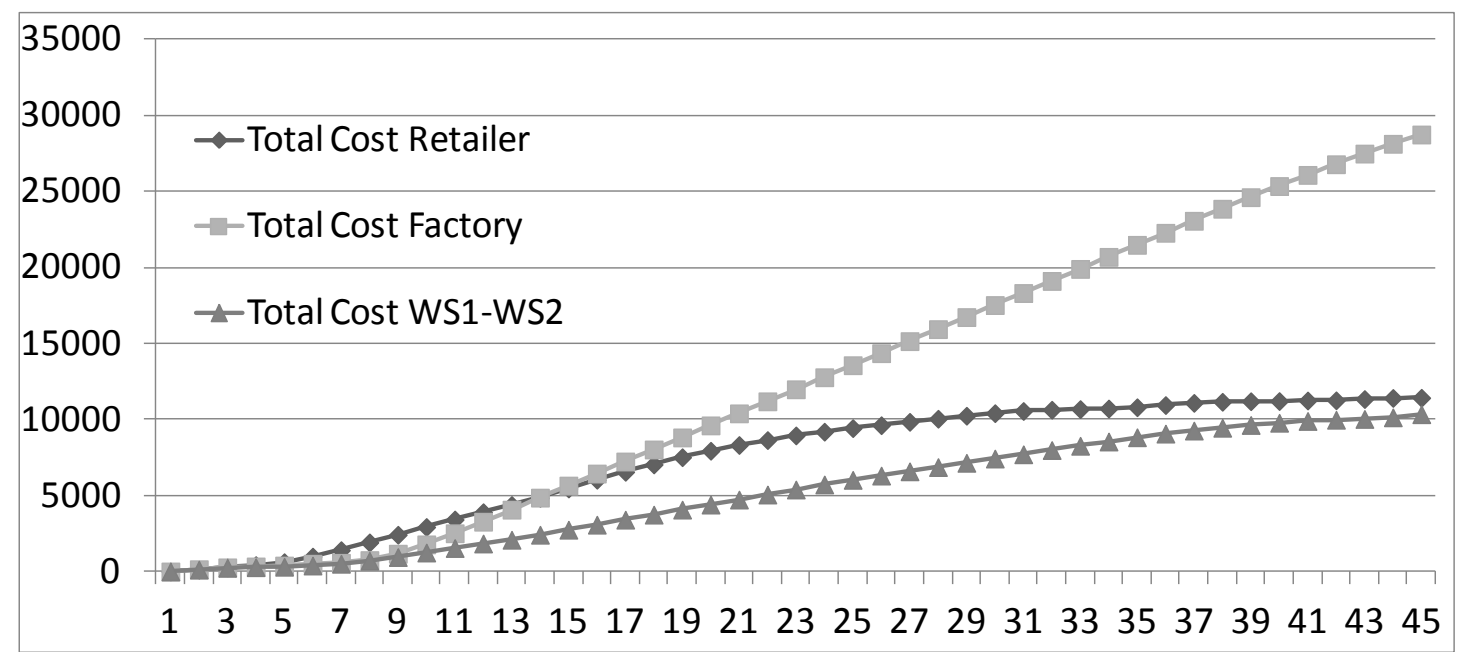

Figure 4. Beer Game 2.1 player's cost

\section{DISCUSSION}

The results of the three simulations can be analyzed from two different perspectives: (i) the policies implemented by each player and (ii) the warehouse and backlog costs. From a methodological point of view, each player was asked to review data collected on his behavior and to describe 
the strategy adopted. As to the cost analysis, data collected on each dashboard were compared.

\subsection{Policies}

The policies implemented by the players can be summed up as follows:

\section{- BEER GAME 1.0}

Factory: On the basis of the first orders, the factory tries to create a warehouse able to meet the market demand, avoid backlogs, and, afterwards, set up a strategy aimed at reducing stock levels (Never Backlog strategy).

Wholesaler no. 1: Wholesaler no. 1 first implements the "Never Backlog" strategy, aiming at stock levels able to successfully meet the estimated maximum market demand (10); then, once he has reached stock levels equal to 10 , he starts sending orders to wholesaler no. 2 equal to the orders received by the distributor (Pass Order strategy).

Wholesaler no. 2: Wholesaler no. 2 uses a balanced strategy in order to have a low-cost warehouse and, at the same time, meet the market demand and avoid backlogs (Full Warehouse).

Retailer: On the basis of the first orders, the retailer tries to create a warehouse able to meet the market demand and, afterwards, set up a strategy aimed at reducing stock levels.

- BEER GAME 2.0

Factory: By adopting a strategy with a cautious attitude toward risk, the factory aims at unsold stock levels capable of satisfying demand from the two middlemen without running the risk of building up a backlog.

Wholesaler no. 1: By adopting a balanced strategy, wholesaler no. 1 aims to keep stocks not particularly high but always capable of serving orders, minimizing costs, and avoiding backlogs.

Wholesaler no. 2: By adopting a strategy with a cautious attitude toward risk, wholesaler no. 2 aims at enough stock levels to avoid building up a backlog and deal with new orders.

Retailer: By adopting a strategy with a cautious attitude to risk, the retailer first aims at a warehouse able to meet the market demand without running the risk of building up a backlog; then, he tries to slowly reduce unsold stock.

- BEER GAME 2.1

Factory: At first, the factory aims at creating a warehouse able to meet the demand of the two middlemen, both of whom are risk subjects. 
Then, the factory assesses the most-suitable strategies to reduce unsold stock.

High-risk wholesaler: At first, the high-risk wholesaler aims at keeping the warehouse at initial levels and then, on the basis of orders received, aims at reducing stock levels and meeting orders received.

Low-risk wholesaler: Aware of playing the role of the "low-risk" middlemen, his main aim is keeping the lowest unsold stock levels.

Retailer: The retailer places substantial orders to both wholesalers aiming at creating a warehouse able to face demand variations and, later on during the game, identifying the riskiest wholesaler in order to reduce stock levels and costs.

Table 2. Policies of players during the simulations

\begin{tabular}{lccc} 
& Beer Game 1.0 & Beer Game 2.0 & Beer Game 2.1 \\
\hline Factory & Never backlog & Never backlog & Full warehouse \\
$\begin{array}{l}\text { Wholesaler no. 1 } \\
\text { (high risk) }\end{array}$ & Pass order & Low cost & Low cost \\
$\begin{array}{l}\text { Wholesaler no. 2 } \\
\text { Retailer }\end{array}$ & Full warehouse & Never backlog & Pass order \\
& Full warehouse & Full warehouse & Never backlog \\
\hline
\end{tabular}

According to the policies described in the above-mentioned matrix and the player's descriptions after the simulations, it is possible to identify two main opposite policies in warehouse management: Never Backlog and Pass Order. In the first policy, players try to foresee customer demand and be always able to satisfy that request. A negative demand variation (near to zero) leads to high stock levels and higher costs that they are not able to reduce.

In the Pass Order policy, the player shows a greater willingness to take risks, as demonstrated by the intention of keeping low stock levels to reduce costs. Delays in goods delivery are common to all players; they have a negative impact on their choice and often lead players to backlog events. Simulations highlight how players were led to make choices on the basis of these two main policies, trying to fill their warehouse or reduce costs and showing higher or lower willingness to take risks.

\subsection{Costs}

During the three Beer Game simulations, we observed that the costs of each player reflected the results of the MIT Beer Game simulation; the player farthest from the market always has higher costs. With the exception 
of the retailer costs (which are always higher in comparison to the wholesaler's in the three simulations), the factory suffers from higher costs due to the total absorption of market demand by the players. This resulted in no supply demand by the wholesalers and the factory's inability to clear unsold stock.

Table 3. Comparison among cost trends in the three simulations

\begin{tabular}{lccc} 
& Beer Game 1.0 & Beer Game 2.0 & Beer Game 2.1 \\
\hline Factory & 11952 & 17490 & 28752 \\
Both wholesalers & 6384 & 14574 & 10348 \\
Retailer & 5508 & 14712 & 11430 \\
\hline
\end{tabular}

A comparison among the cost trends in the three simulations is extremely interesting. A significant cost increase can be observed between Beer Game 1.0 and Beer Game 2.0 due to an insufficient market demand towards the supply chain (this also led to no player demand and stagnation of goods in most warehouses). During simulation Beer Game 2.1, the two wholesalers were given different costs on the basis of their attitude towards risk. For this reason, they enjoyed lower costs in comparison to the retailer and made their supply chain more cost efficient.

\section{DISCUSSION AND CONCLUSION}

Following an introduction to the MIT Beer Game, the characteristics of two new versions of the simulation tool were presented that take into account virtual enterprise variables. A series of simulations was carried out on the three versions of the tool, and the results were comparatively analyzed. Finally, through the analysis of simulation data and a focus group with the players, we were able to outline their policies.

Both the MIT Beer Game and its evolutions share a number of limitations that can be the basis for further research in this domain. The structural complexity of virtual enterprises is not reflected in the topology of the new versions of the Beer Game, which is still based on two parallel lines. This choice allowed creation of simple tools that do not need the support of an IT platform for running the simulation. The effectiveness of this approach needs to be demonstrated by assessing the learning objectives achieved by a group of users playing with different versions of the Beer Game. Finally, the three simulations were carried out by the same group of students from the LUISS ETC course. Therefore, data may be affected from some bias due to the learning processes of students. Possible directions to 
further develop the empirical part of this work are related to the i) collection of more data and (ii) simulation of a supply chain where information is suddenly available for each player without having a slow information flow as it happens with goods delays. In this case, we expect that players will easily adopt a low-cost policy, able to rely on a strongly integrated supply chain.

This study offers two main contributions. First, it increases understanding of the complexity of managing decision making in supply chains and networks. Indeed, Never Backlog, Full Warehouse, Low Cost, and Pass Order options emerged as policies adopted by the players. These policies were analyzed with respect to their relationship with the structure of the supply chain. The second contribution is related to simulation studies ${ }^{24}$ and the availability of a new teaching tool ${ }^{25}$ to show students the different implications of a supply chain that takes into account topology, transaction costs, and risks. The feedback collected from the participants demonstrated that by using this simulation tool, it is possible to critically analyze the decision making process and understand the foundation of the policies adopted by the managers.

\section{REFERENCES}

[1] A. D'Atri, P. Spagnoletti, A. Banzato, C. Bonelli, E. D'Atri, V. Traversi, and P. Zenobi, From supply chains to supply networks: The beer game evolution. Paper presented at 13th IFAC Symposium on Information Control Problems in Manufacturing, Moscow, Russia, June 3-5, 2009.

[2] J.D. Sterman, Instructions for running the beer distribution game (D-3679), Sloan School of Management, MIT, 1984.

[3] J.C. Anderson, Dyadic business relationship within a business network context. Journal of Marketing, 58(4), p1-15, 1994. http://dx.doi.org/10.2307/1251912.

[4] H.L. Lee, V. Padmanabhan, S. Whang, The bullwhip effect in supply chains. Sloan Management Review, 38(3), p93-102, 1997.

[5] V. Shuklaa, M.M. Naima, and E.A. Yaseenb, 'Bullwhip' and 'backlash' in supply pipelines. International Journal of Production Research, 47(23), p6477-6497, 2009. http://dx.doi.org/10.1080/00207540802270096.

[6] P. Kaminsky, and D. Simchi-Levi, A new computerized beer game: A tool for teaching the value of integrated supply chain management. In H.L. Lee, and N.G. Shu Ming (Eds.), Global Supply Chain and Technology Management (p216-225). Miami, Florida: The Production and Operations Management Society, 1998. 
[7] S.O. Kimbrough, D.J. Wu, and F. Zhong, Computers play the beer game: Can artificial agents manage supply chains? Decision Support Systems, 33(3), p323-333, 2001. http://dx.doi.org/10.1016/S0167-9236(02)00019-2.

[8] F. Chen, and F. Samroengraja, The stationary beer game. Production and operations management. Production and Operations Management, 9(1), p19-30,

2000. http://dx.doi.org/10.1111/j.1937-5956.2000.tb00320.x.

[9] M. Holweg, and J. Bicheno, Supply chain simulation - A tool for education, enhancement and endeavour. International Journal of Production Economics, 2(21), p163-175, 2002. http://dx.doi.org/10.1016/S0925-5273(00)00171-7.

[10] S. Kumara, C. Chandrab, and M.S. Seppanenc, Demonstrating supply chain parameter optimization through beer game simulation. Information Knowledge Systems Management, 6(4), p291-322, 2007.

[11] K.T. Hung, and S. Ryu, Changing risk preferences in supply chain inventory decisions. Production Planning \& Control, 19(8), p770-780, 2008. http://dx.doi.org/10.1080/09537280802550146.

[12] B.M. Beamon, Supply chain design and analysis: Models and methods. International Journal of Production Economics, 55(3), p281-294, 1998. http://dx.doi.org/10.1016/S0925-5273(98)00079-6.

[13] J.A.D. Machuca, and R. Del Pozo Barajas, A computerized network version of the Beer Game via the Internet. System Dynamics Review, 13(4), p323-340, 1997. http://dx.doi.org/10.1002/(SICI)1099-1727(199724)13:4<323::AID-SD R135>3.0.CO;2-O.

[14] P.M. Reyes, Parallel interaction supply chain game: An extension of the beer game. Decision Sciences Journal of Innovative Education, $5(2)$, p413-421, 2007. http://dx.doi.org/10.1111/j.1540-4609.2007.00151.x.

[15] R. Norman, and R. Rafael, From value chain to value constellation: Designing interactive strategy. Harvard Business Review, 71(4), p65-77, 1993.

[16] M.T. Martinez, P. Fouletier, K.H. Park, and J. Favrel, Virtual enterprise - Organisation, evolution and control. International Journal of Production Economics, 74(1-3), p225-238, 2001. http://dx.doi.org/10.1016/S0925-5273(01)00129-3.

[17] P. Spagnoletti, and S. Za, A design theory for e-service environments: the interoperability challenge. In M. Snene (Ed.), IESS 2012, LNBIP 103 (p201-211). Berlin Heidelberg: Springer-Verlag, 2012. http://dx.doi.org/10.1007/978-3-642-28227-0_15.

[18] A.M. Braccini, P. Spagnoletti, and A. D'Atri, Defining cooperative business models for interorganizational cooperation. International 
Journal of Electronic Commerce Studies, 3(2), p229-249, 2012. http://dx.doi.org/10.7903/ijecs.1093.

[19] K. Lajili, and J.T. Mahoney, Revisiting agency and transaction costs theory predictions on vertical financial ownership and contracting: Electronic integration as an organizational form choice, Managerial and Decision Economics, 27(7), p573-586, 2006. http://dx.doi.org/10.1002/mde.1275.

[20] O. Williamson, The economics of organization: The transaction cost approach. American Journal of Sociology, 87(3), p548-577, 1981. http://dx.doi.org/10.1086/227496.

[21] A. D'Atri, and A. Motro, VirtuE: A formal model of virtual enterprises for information markets. Journal of Intelligent Information Systems, 30(1), p33-53, 2008. http://dx.doi.org/10.1007/s10844-006-0013-0.

[22] K. Riemer, The Beergame in business-to-business ecommerce courses A teaching report. Paper presented at the 21th Bled eConference eCollaboration: Overcoming Boundaries through Multi-Channel Interaction, Bled, Slovenia, June 15-18, 2008.

[23] T.H. Davenport, and J.G. Harris, Automated decision making comes of age. MITSloan Management Review, 46(4), p83-89, 2005.

[24] S. Za, and P. Spagnoletti, Knowledge creation processes in information systems and management: Lessons from simulation studies. In P. Spagnoletti (Ed.), Organization Change and Information Systems (p191-204). Heidelberg: Springer, 2013

[25] A. North-Samardzic, A.M. Braccini, P. Spagnoletti, and S. Za, Applying media synchronicity theory to distance learning in virtual worlds: a design science approach. International Journal of Innovation and Learning, forthcoming. 